\title{
Break Down of Tracheostomy Tube in A 3-Year-Old Girl: A Case Report
}

\author{
Haifa Al-Otaibi* and Mishal Al-Mutairi \\ Zain hospital, Ministry of Health, Kuwait
}

Submission: October 15, 2018; Published: October 24, 2018

*Corresponding author: Haifa Al Otaibi, Zain hospital, Ministry of Health, Kuwait

\begin{abstract}
Objective: We aimed to educate readers about the importance of proper tracheostomy care by following preventive measures.

Case Presentation: A 3 year-old girl presented to the emergency room with a history of tracheostomy tube (t-tube) separation from the flange during routine suctioning at home. She had also experienced a brief cyanotic attack previously. An urgent neck X-ray revealed a separated $\mathrm{t}$-tube within the trachea. We extracted the $\mathrm{t}$-tube from the left main bronchus using a rigid bronchoscope, and the $\mathrm{t}$-tube was changed.

Conclusion: Rigid bronchoscopy has both diagnostic and therapeutic applications. Close follow-up and scheduled tube changing are essential for preventing this complication.
\end{abstract}

Keywords: Tracheostomy; break down; otolaryngology

\section{Significance of the Study}

We present a rare tracheostomy complication related to a manufacturing defect. Following t-tube aspiration, our patient suffered a brief cyanotic attack. She was immediately taken to the operating room, and the broken t-tube was removed. We seek to educate readers about the importance of proper tracheostomy care.

\section{Introduction}

Tracheostomy tube (t-tube) break down is a rare but lifethreatening complication that can be prevented by following several preventive measures. Few such incidents, mainly in developing countries, have been reported in the literature, indicating ineffective tracheostomy care as the leading cause. We report the case of a girl with $\mathrm{t}$-tube break down, where the most likely cause was a manufacturing defect.

\section{Case Report}

A 3 year old girl had a history of Down syndrome and bilateral choanal atresia with recurrent restenosis. She had undergone tracheostomy at age 3 months. She presented to the ENT emergency department in Sabah hospital with a history of t-tube separation from the flange during routine suctioning at home. When changing the t-tube, her mother noticed that the old tube was missing and immediately took her to our hospital. Prior to presentation, the patient had experienced a brief cyanotic attack. On presentation, she was distressed, with an oxygen saturation of $99 \%$ in room air. Her heart rate was $155 \mathrm{bpm}$, and her temperature was $36.1^{\circ} \mathrm{C}$. On auscultation, there were equal bilateral air entry and secretion sounds. Anterior, posterior, and lateral neck X-rays revealed a separated t-tube within the trachea (Figures $1 \& 2$ ). The patient was immediately taken to the operating room, and she underwent diagnostic fiber optic bronchoscopy. A portion of the t-tube was revealed within the trachea, near the carina. The dislodged t-tube, which had inner and outer diameters of 3 and $4.2 \mathrm{~mm}$, respectively, was extracted from the left main bronchus with a rigid bronchoscope (size 3.7 $\mathrm{mm}$ ) (Figure 3). Finally, the t-tube was changed. After recovery, the patient was transferred to the pediatric intensive care unit for close observation. A repeat chest X-ray revealed normal findings. The next day, she was transferred to the general ward and was doing well. Her vital signs were normal, and oxygen saturation was found to be $98 \%$ in room air.

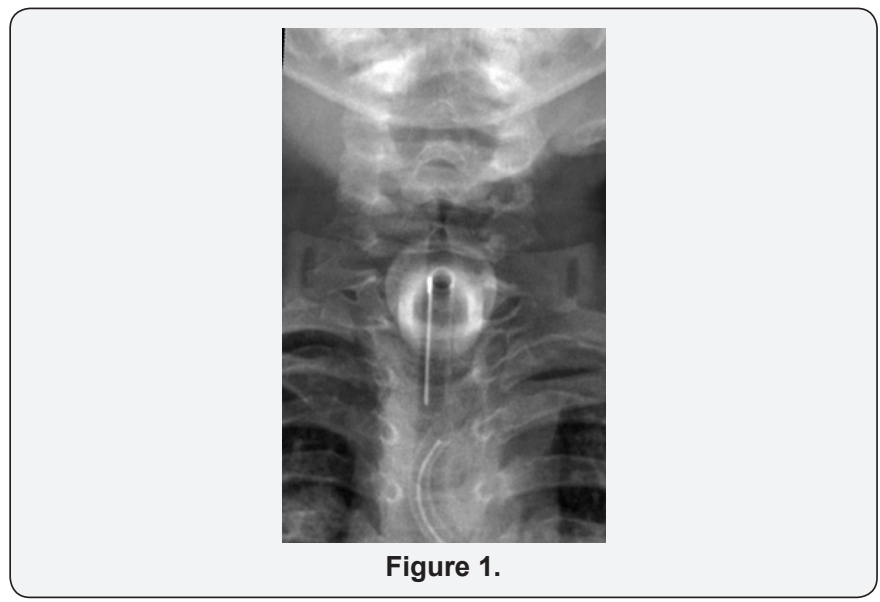




\section{Global Journal of Otolaryngology}
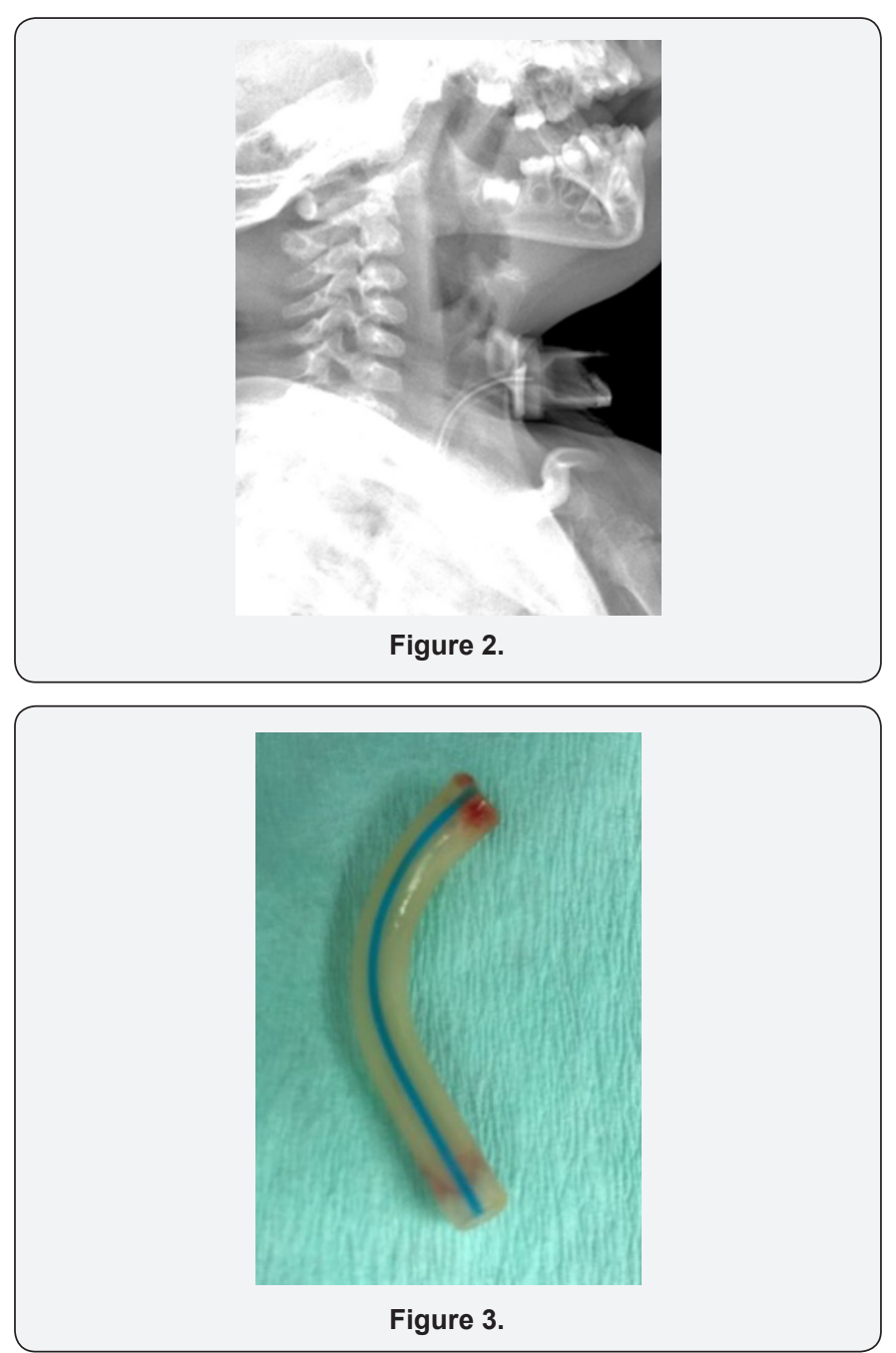

\section{Discussion}

Tracheostomy is a lifesaving procedure to create a surgical airway in the cervical trachea. However, the procedure is associated with several complications such as tracheal or subglottic stenosis, granulation tissue formation, and decannulation difficulties, which are common late problems in children. T-tube break down is one such rare complication. It was first reported by Bassoe and Boe [1]. Most of the cases reported in the literature are associated with metallic tracheostomy tubes; however, cases of fractured synthetic tubes, similar to that in our case, are also reported. Synthetic tube fractures are associated with mechanical defects, mainly involving the fused joint at the junction of the tube and neck plate [2]. Moreover the type of synthetic material and the likelihood of degradation were subjects of previous studies. One such study found silicone to be the most stable t-tube material. Several factors were associated with a high risk of t-tube breakage such as manufacturing defects, alkaline bronchial secretions, repeated sterilization, and tube deterioration due to lack of patient follow-up and infrequent tube changes [3]. Early fractures are often associated with manufacturing defects or a malfunction. This was the most likely cause in our case because the patient's caregiver performed regular t-tube changes. Our patient presented with foreign body aspiration and a history of brief cyanotic attack. From our review of the literature, most patients do not present with serious complications unless the tube blocks the airway. In our case, t-tube aspiration occurred during suctioning at home. A similar case was reported in a hospital, after which the broken piece was immediately retrieved with artery forceps through stoma exploration [3]. X-rays of the neck and chest may aid in diagnosis and location of the foreign body. Prompt treatment and removal of the foreign body are essential. Removal of the broken piece with a rigid bronchoscope under general anesthesia should be considered the treatment of choice [4]. Several preventive measures have been mentioned in the literature, including regular follow-up and tube changes, careful tracheostomy dressing changes, and gentle t-tube cleaning [5]. During follow-up, doctors should examine the t-tube for evidence of impending fracture.

\section{Conclusion}

T-tube breakage is a rare but possibly life-threatening complication. Prompt diagnosis and management with rigid bronchoscopy are essential. Finally, close follow-up and regular scheduled tube changes are important steps that may help prevent

\section{References}

1. Bassoe HH, Boe J (1960) Broken tracheostomy tube as a foreign body. Lancet 7132: 1006-1007. https://www.ncbi.nlm.nih.gov/ pubmed/?term $=1 . \% 09$ Bassoe + HH\% $\quad 2 \mathrm{C}+$ Boe + J.+(1960) + Broken + tracheostomy+tube+as $+a+$ foreig $n+b o d y .+$ Lancet. $\% 3 B+$ 1\%3A1006\%E2\%80\%931007

2. Lynrah ZA, Goyal S, Goyal A, Lyngdoh NM, Shunyu NB, Baruah B, Dass R, Yunus M, Bhattacharyya P (2012) Fractured tracheostomy tube as foreign body bronchus: Our experience with three cases. International Journal of Pediatric Otorhinolaryngology 76(11): 1691-169. https:// doi.org/10.1016/j.ijporl.2012.07.033

3. Parida PK, Kalaiarasi R, Gopalakrishnan S, Saxena SK (2014) Fractured and migrated tracheostomy tube in the tracheobronchial tree. International Journal of Pediatric Otorhinolaryngology 78(9): 14721475. https://doi.org/10.1016/j.ijporl.2014.06.011

4. So-Ngern A, Boonsarngsuk V (2016) Fractured metallic tracheostomy tube: A rare complication of tracheostomy. Respiratory medicine case report 19: 46-48 https://doi.org/10.1016/j.rmcr.2016.07.007

5. Herrag M, Sajiai H, Rochdi Y, Lahmiti S, Dannaoui Y, Raji A, Yazidi AA (2011) Flexible bronchoscopic removal of a fractured metallic tracheostomy tube. Bronchol Intervent Pulmonol 18(2): 164-167. https://www.ncbi.nlm.nih.gov/pubmed/23169088 


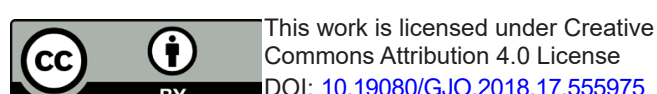

DOI: 10.19080/GJO.2018.17.555975

\section{Your next submission with Juniper Publishers will reach you the below assets}

- Quality Editorial service

- Swift Peer Review

- Reprints availability

- E-prints Service

- Manuscript Podcast for convenient understanding

- Global attainment for your research

- Manuscript accessibility in different formats

( Pdf, E-pub, Full Text, Audio)

- Unceasing customer service

Track the below URL for one-step submission https://juniperpublishers.com/online-submission.php 